\title{
Eco-friendly polydimethylsiloxane-based self-supporting film containing europium-polyoxometalate: A flexible luminescent material for white light generation
}

\author{
Mateus Batista Simões ${ }^{\mathrm{a}}$, Sajjad Ullah ${ }^{\mathrm{b}, \mathrm{c}}$, Chanchal Hazra ${ }^{\mathrm{b}}$, Michel Wong Chi Man ${ }^{\mathrm{d}}$, \\ Sidney José Lima Ribeiro ${ }^{\mathrm{b}}$, Ubirajara Pereira Rodrigues-Filho, \\ a Instituto de Química de São Carlos, Universidade de São Paulo, 13560-970 São Carlos, SP, Brazil \\ ' Instituto de Química, Universidade Estadual Paulista "Júlio de Mesquita Filho", 14800-060 Araraquara, SP, Brazil \\ ${ }^{\mathrm{c}}$ Institute of Chemical Sciences, University of Peshawar, 25120 Peshawar, KP, Pakistan \\ dinstitut Charles Gerhardt Montpellier, UMR 5253 CNRS-ENSCM-UM, 8 rue de l'école normale, 34296 Montpellier Cédex 05, France
}

\section{A R T I C L E I N F O}

\section{Keywords:}

Lanthanide

Hybrid matrix

Polyhydroxyurethane

White light

\begin{abstract}
A B S T R A C T
Lanthanide $\left(\mathrm{Ln}^{3+}\right)$-doped suitable matrices exhibit unique luminescent properties which are important for applications in optoelectronic devices. Most of the $\mathrm{Ln}^{3+}$-based luminescent materials are, however, prepared in powder form using suitable robust inorganic host matrices. These matrices, often, experience lack of flexibility which is important for many applications such as LEDs and wearable devices, among others. To address this aspect, we report the preparation of flexible and highly transparent luminescent membranes based on polydimethylsiloxane-hydroxyurethanes (PDMSUr) as the hybrid framework and Europium-polyoxometalate (Eu $\left(\mathrm{PW}_{11}\right)_{2}$ ) complex as the luminescent component. The PDMSUr, besides acting as green, transparent and flexible matrix, is found to increase the emission decay lifetime (from $1.5 \mathrm{~ms}$ to $3.0 \mathrm{~ms}$ ) when $\mathrm{Eu}\left(\mathrm{PW}_{11}\right)_{2}$ is incorporated in the hybrid matrix. Moreover, upon UV excitation, the matrix exhibits a broader emission around $450 \mathrm{~nm}$ which, together with the characteristic emission of $\mathrm{Eu}^{3+}$ ions, leads to the generation of white light.
\end{abstract}

\section{Introduction}

Lanthanide $\left(\mathrm{Ln}^{3+}\right)$-doped materials have several applications such as in the development of new phosphors for display and lighting and laser crystals, to name a few [1-5]. The most interesting characteristic of $\mathrm{Ln}^{3+}$ ions is their sharp transitions arising due to intra $4 \mathrm{f}$ transitions, which are generally shielded by the outer 5 s and $5 p$ orbitals [6-8]. Despite the fact that these parity forbidden transitions have low absorption coefficients, the longer luminescence lifetime ( $\mu$ s to ms) possessed by the $\mathrm{Ln}^{3+}$ excited states are explored for many optoelectronic applications [9-12]. In addition to the ligands-induced Stokes shifted luminescence, they possess the ability to exhibit anti-Stokes emissions, a phenomenon generally known as the upconversion process [13-15].

The $\mathrm{Ln}^{3+}$ ions, however, usually do not exhibit downshifting (or downconversion) and upconversion (UC) luminescence in their free state (except $\mathrm{Ln}^{3+}$ ions in gas or liquid state) at room temperature. In order to resolve this issue, $\mathrm{Ln}^{3+}$ ions are necessary to be doped in appropriate host matrices, either by incorporation [16] or by direct covalent binding $[17,18]$. Generally, a suitable host material is one which has high transparency in the wavelength range of interest, has low phonon energy and good photostability. The most common matrices for $\mathrm{Ln}^{3+}$ ions include inorganic oxides $\left(\mathrm{Y}_{2} \mathrm{O}_{3}, \mathrm{Gd}_{2} \mathrm{O}_{3}\right)$ [19-21], halides $\left(\mathrm{NaYF}_{4}, \mathrm{LiYF}_{4}\right)$ [22], vanadate $\left(\mathrm{YVO}_{4}, \mathrm{GdVO}_{4}\right)$ [23-25], sulfate $\left(\mathrm{NaGd}\left(\mathrm{SO}_{4}\right)_{2}\right)[26]$ and polyoxometalates (POMs) and their derivatives [27]. The halides-based materials possess low phonon energies $\left(<350 \mathrm{~cm}^{-1}\right)$ but they are hygroscopic in nature. Oxides, on the other hand, are chemically stable but their phonon energies are relatively high $\left(>500 \mathrm{~cm}^{-1}\right)[28,29]$. The inorganic matrices mentioned above thus present some disadvantages considering their poor mechanical properties and challenging processing. From application point of view, high processability and good flexibility are other important parameters for selection of a suitable host material. Thus the development of polymer and/or hybrid-based matrices as flexible substrates for $\mathrm{Ln}^{3+}$ ions is an interesting strategy to obtain advanced functional materials $[3,16,30]$. Polymeric and hybrid matrices are important as they carry inherent advantages such as easier patterning, higher flexibility, improved mechanical, thermal and optical properties, raising the number of possible applications of lanthanides-based materials [30]. Moreover, these matrices are of great interest for optical and photonics application as they may be obtained through environmental friendly and

\footnotetext{
* Corresponding author

E-mail address: ubirajara@usp.br (U.P. Rodrigues-Filho).
} 
sustainable routes, leading to the development of so-called green photonics [31]. For instance, increasing $\mathrm{CO}_{2}$ concentration and its effects on climatic changes, as stated by the Intergovernmental Panel on Climate Change (IPCC), are problems that need to be addressed as soon as possible [32] and any chemical strategy that consumes or fixes $\mathrm{CO}_{2}$ and converts it into innovative materials are highly welcomed [33-37].

Keeping in view the flexibility and practicality of polymeric materials and the importance of synthetic strategies for $\mathrm{CO}_{2}$ mitigation, we have come up with the idea to utilize PDMSUr hybrid, self-supporting membranes as a green flexible matrix material for immobilizing Eupolyoxometalates $\left(\mathrm{Eu}\left(\mathrm{PW}_{11}\right)_{2}\right)$ complex which renders the polymeric films their luminescent properties. The PDMSUr hybrid matrix is derived from cyclic carbonates (CC) which are in turn obtained from chemical fixation of $\mathrm{CO}_{2}$ into oxirane rings. Besides the $\mathrm{CO}_{2}$ fixation, this methodology also provides a way to substitute the polyurethanes (PUs) and consequently avoiding the utilization of known toxic and hazardous phosgene and isocyanates [38-41]. Moreover, the additional hydroxyl group provides higher chemical and hydrolysis resistance to polyhydroxyurethanes (PHUs) compared to traditional PUs [41]. Considering these features, PHUs finds applications in a wide range of technological fields, highlighting foams [42,43], drug delivery [44], protective coatings $[38,45]$, insulators [43] and adhesives [46]. However, these materials have not been exploited for their applications in optic and photonic fields, an aspect that is the subject of this study.

In this work, telechelic diglycidylether polydimethylsiloxane (PDMS) was converted to the corresponding cyclic carbonate (CCPDMS) which on reaction with isophorene diamine (IPDA) as chain extender and with 3-aminopropyltriethoxysilane (APTES) as endstopper yielded PDMSUr hybrid matrix. To the best of our knowledge, there is no report on the use of this flexible and greener matrix (obtained from a $\mathrm{CO}_{2}$ fixation route in an environmental friendly way) for photonic applications. The proposed matrix presents high transmittance ( $>96 \%$ ) over all visible region and allows easy processing to obtain self-supporting films modified with europium polyoxometalate complex [Eu( $\left.\left(\mathrm{PW}_{11}\right)_{2}\right]$, thus leading to development of white emitters. Considering the innate emission from the matrix and its filmogenic nature, we show the suitability of the hybrid PDMSUr matrix to achieve self-supporting and flexible white-emitting membrane. The results obtained could be considered as step forward towards the development of green photonics.

\section{Materials and methods}

\subsection{Synthesis of telechelic cyclic carbonate polydimethylsiloxane (CCPDMS)}

Synthesis of CCPDMS precursor was performed as previously described [47]. Briefly, $10 \mathrm{~g}$ of diglycidylether terminated PDMS (SigmaAldrich) were dissolved in $40 \mathrm{~mL}$ of 2-ethoxyethanol (Merck) containing $0.1 \mathrm{~g}$ of tetrabutylammonium bromide (Sigma-Aldrich) as catalyst. The resulting solution was transferred to a stainless-steel Parr Reactor (model 4843), purged with $\mathrm{CO}_{2}$ (Linde), sealed and heated at $150{ }^{\circ} \mathrm{C}$ under 160 PSI of $\mathrm{CO}_{2}$ for $8 \mathrm{~h}$. Afterwards, the material was purified via solvent extraction (water-ethyl acetate) and the catalyst was recovered.

\subsection{Synthesis of europium polyoxometalate complex}

Organics-soluble $\mathrm{Eu}\left(\mathrm{PW}_{11}\right)_{2}$ was synthesized according to previous report with minor modifications [48]. For this purpose, we first synthesized the ligand $\mathrm{PW}_{11}$ as follows: $22 \mathrm{mmol}$ of $\mathrm{Na}_{2} \mathrm{WO}_{4} \cdot 2 \mathrm{H}_{2} \mathrm{O}$ (Fluka) were dissolved in $15 \mathrm{~mL}$ of deionized water, followed by the addition of $2.5 \mathrm{~mL}$ of $\mathrm{H}_{3} \mathrm{PO}_{4}\left(1 \mathrm{~mol} \mathrm{~L}^{-1}\right)$ and $4.4 \mathrm{~mL}$ of glacial acetic acid. The resulting solution was refluxed at $90^{\circ} \mathrm{C}$ for $1 \mathrm{~h}$ using an oil bath. The resulting solution was allowed to cool down to room temperature and formation of $\mathrm{K}_{7}\left(\mathrm{PW}_{11} \mathrm{O}_{39}\right) \cdot \mathrm{xH}_{2} \mathrm{O}\left(\mathrm{PW}_{11}\right)$ crystals was induced by the addition of $\mathrm{KCl}$. The obtained $\mathrm{PW}_{11}$ crystals were filtered off and dried at $60{ }^{\circ} \mathrm{C}$ during $24 \mathrm{~h}$. An aqueous solution $(9 \mathrm{~mL}$ ) containing $0.5 \mathrm{mmol}$ of the synthesized ligand $\left(\mathrm{PW}_{11}\right)$ was prepared and then mixed with $1 \mathrm{~mL}$ of $\mathrm{EuCl}_{3}$ solution $(0.25 \mathrm{mmol})$ obtained by dissolving $\mathrm{Eu}_{2} \mathrm{O}_{3}$ (Sigma-Aldrich) in $\mathrm{HCl}$. The mixed solution was refluxed for $1 \mathrm{~h}$ and then allowed to cool down to room temperature. The organic soluble Eu $\left(\mathrm{PW}_{11}\right)_{2}$ complex was precipitated from addition of excess of tetrabutylammonium bromide, where tetrabutylammonium acts as counterion for the complex $\mathrm{Eu}\left(\mathrm{PW}_{11} \mathrm{O}_{39}\right)_{2}{ }^{11}$. The complex was filtered off and dried at $60^{\circ} \mathrm{C}$ for $24 \mathrm{~h}$.

\subsection{Synthesis of PDMSUr films containing $\mathrm{Eu}\left(P W_{11}\right)_{2}$}

$0.45 \mathrm{~g}$ of purified CCPDMS was mixed with $69.3 \mu \mathrm{L}$ of isophorene diamine (IPDA - Sigma-Aldrich) and the mixture was heated at $70{ }^{\circ} \mathrm{C}$ under magnetic stirring. After $20 \mathrm{~min}$ of reaction, $263 \mu \mathrm{L}$ of APTES (Sigma-Aldrich) was added and the reaction mixture was held for $20 \mathrm{~min}$ at $70^{\circ} \mathrm{C}$, yielding the PDMSUr hybrid matrix. To prepare the membranes containing the $\mathrm{Eu}\left(\mathrm{PW}_{11}\right)_{2}$, the freshly prepared PDMSUr matrix was solubilized in $2.5 \mathrm{~mL}$ of N,N-dimethylacetamide (SigmaAldrich) containing $45 \mathrm{mg}$ of the solubilized $\mathrm{Eu}\left(\mathrm{PW}_{11}\right)_{2}$. The resulting solution was homogenized under vigorous magnetic stirring for $30 \mathrm{~min}$ and then transferred to a Teflon mold to obtain self-supported films by casting method. The materials were allowed to dry at $60^{\circ} \mathrm{C}$ for $24 \mathrm{~h}$.

\subsection{Characterizations}

Fourier transformed infrared analysis (FTIR) spectra of the sample mixed $\mathrm{KBr}$ were acquired with a Shimadzu (model IRAffinity) Spectrophotometer at a resolution of $4 \mathrm{~cm}^{-1}$ in transmittance mode $\left(4000-400 \mathrm{~cm}^{-1}\right)$ or attenuated total reflectance (ATR) mode (4000-650 $\mathrm{cm}^{-1}$ ) employing a ZnSe crystal. Raman spectra were collected with a CRAIC microspectrophotometer, employing an 830-nm laser, $49.8 \mathrm{~mW}$ power, $10 \mathrm{~s}$ exposure time and 15 scans. Photoluminescence (PL) studies were performed using a Horiba Jobin Yvon Fluorolog-3 machine (USA); FL3-122 model; spectrometer equipped with $450 \mathrm{~W}$ Xe continuous lamp. A double grating monochromator (resolution of $0.3 \mathrm{~nm}$ ) was used to disperse the excitation and emission radiation and a photomultiplier tube (model R $928 \mathrm{P}$ from Spex $180-850 / 860 \mathrm{~nm}$ ) was used as the photon detector. For measurement of the PL emission spectra, the excitation and emission slit widths were fixed at $5 \mathrm{~nm}$ and $0.5 \mathrm{~nm}$, respectively and the integration time was set to $1 \mathrm{~s}$. For low temperature $(77 \mathrm{~K})$ measurements, the sample membrane was cut into small piece held inside a quartz tube. The quartz tube was then placed inside a Dewar flask filled with liquid nitrogen. The PL lifetime measurements were performed in triplicate using a Xenon pulsed bulb with $0.15 \mathrm{~J}$ per flash. The transmittance of the films in the $200-1000 \mathrm{~nm}$ range was measured using a Shimadzu UV-Vis spectrophotometer (model UV1800). For measurement of the $\% \mathrm{~T}$, the sample precursor was coated as a film (of thickness similar to that of self-supporting hybrid membranes) on quartz plates and it electronic spectra were obtained using a clean quartz plate as reference or background. Thermogravimetric analysis was performed with a Shimadzu TGA 50 instrument (heating rate $5{ }^{\circ} \mathrm{C} \mathrm{min}{ }^{-1}$, temperature window $25-800{ }^{\circ} \mathrm{C}, \mathrm{N}_{2}$ flow).

\section{Results and discussion}

\subsection{Characterization of PDMSUr matrix containing $E u\left(P W_{11}\right)_{2}$}

Before studying their photoluminescence behavior, the PDMSUr-Eu $\left(\mathrm{PW}_{11}\right)_{2}$ materials were characterized by FTIR spectroscopy, electronic spectroscopy and Raman spectroscopy. A more detailed description of the PDMSUr materials can be found in previous reports by our research group $[45,47]$.

The preparation of the CCPDMS precursor from $\mathrm{CO}_{2}$ fixation and the 


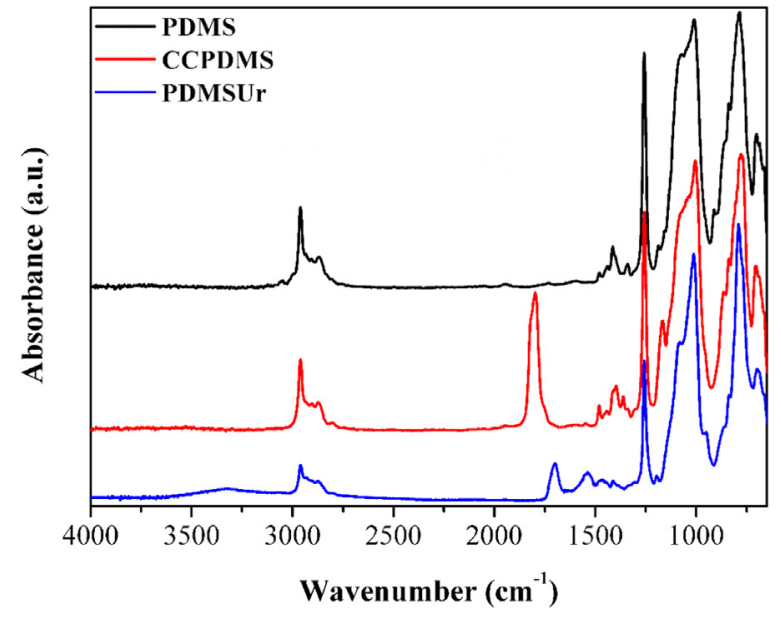

Fig. 1. ATR-FTIR spectra of the PDMS, CCPDMS and PDMSUr materials.

subsequent formation of the hybrid PDMSUr material was monitored by FTIR (Fig. 1). The appearance of a sharp and intense band in the $1800 \mathrm{~cm}^{-1}$, which corresponds to the carbonyl group of cyclic carbonates, confirms the formation of CCPDMS. The vibrational modes observed in the $3000-2800 \mathrm{~cm}^{-1}$ region correspond to the methyl groups of PDMS segment and those observed at $1257 \mathrm{~cm}^{-1}$ and $777 \mathrm{~cm}^{-1}$ correspond to the $\mathrm{Si}-\mathrm{CH}_{3}$ groups. The vibrational peaks in $1100-1000 \mathrm{~cm}^{-1}$ region are related to the siloxane bonds [47]. After reaction with the amino groups from IPDA and APTES, polyhydroxyurethane are obtained as confirmed by the emergence of a broad peak in $3300 \mathrm{~cm}^{-1}$ (OH groups) and dislocation of the characteristic peak of carbonyl group (urethane bond) to $1703 \mathrm{~cm}^{-1}$. Moreover, the new peak emerging at around $1537 \mathrm{~cm}^{-1}$ is also attributed to the NH-urethane bond [47].

One key feature of this hybrid PDMSUr matrix is its ability to allow easy patterning and form self-supporting transparent films and coatings. Since one of the desired properties of any matrix for potential applications in photonic and optical fields is adequate transparency in the wavelength range of interest, we evaluated the transmittance characteristic of PDMSUr matrix in the $200-1000 \mathrm{~nm}$ region (Fig. 2).

Importantly, the hybrid PDMSUr matrix presents high transmittance, over $96 \%$, in the whole visible to near infrared (NIR) region (400-1000 nm), making this material particularly relevant for photonic and optical applications, especially the development of white light emitters. In the UV region, however, strong absorption is observed slightly above $250 \mathrm{~nm}$ ( $\pi-\pi *$ transition) and around $277 \mathrm{~nm} \mathrm{(n-}$ $\pi *$ transitions) of the carbonyl groups of urethane bond [49].

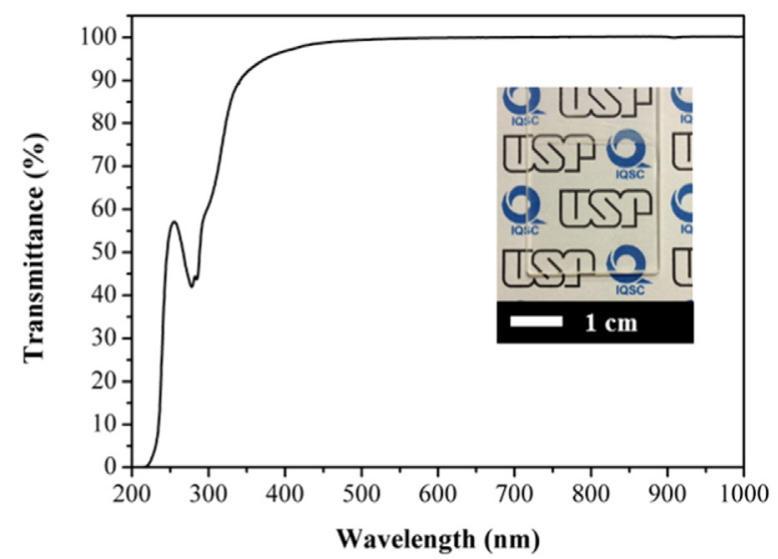

Fig. 2. Transmittance spectrum of the PDMSUr matrix. Inset: digital photograph showing the high transparency of the PDMSUr film.

\subsection{Characterization of $\mathrm{Eu}\left(P \mathrm{~W}_{11}\right)_{2}$ Complex}

Considering the high transparency of the PDMSUr matrix in visible/ NIR region (Fig. 2) and its flexibility, we modified this material with luminescent ions to evaluate its potential application in photonics. Considering its luminescent characteristics [48] and its positive contribution on the mechanical properties of the PDMSUr matrix [45], we chose $\mathrm{Eu}\left(\mathrm{PW}_{11}\right)_{2}$, a complex between $\mathrm{Eu}^{3+}$ and a lacunary specie of Keggin-type polyoxometalate $\left(\left(\mathrm{PW}_{11} \mathrm{O}_{39}\right)^{7-}\right)$, to modify the PDMSUr matrix and obtained very homogenous, self-supporting hybrid luminescent films which emit white light upon UV excitation.

The Eu( $\left(\mathrm{PW}_{11}\right)_{2}$ complex, however, was separately characterized before being added to the PDMSUr matrix. The polyoxometalate we employed is a lacunary species with 4 chelating points which can complex $\mathrm{Eu}^{3+}$ ion in an octacoordination mode, protecting the lanthanide ion from possible quenchers from the matrix and/or medium. Thus, the first step was the synthesis of the $\mathrm{PW}_{11}$ lacunary ligand, followed by a stoichiometric reaction with $\mathrm{Eu}^{3+}$ ions to obtain $\mathrm{Eu}\left(\mathrm{PW}_{11}\right)_{2}$ complex. This complex is usually obtained as sodium and/or potassium salts, but we modified the method to obtain it as tetrabutylammonium salt which gives higher solubility in organic medium [50,51], making it more compatible and soluble in PDMSUr matrix. The formation of Eu $\left(\mathrm{PW}_{11}\right)_{2}$ complex was followed by FTIR and Raman spectroscopies (Fig. S1, Supplementary information).

The FTIR spectra of $\mathrm{PW}_{11}$ ligand shown in Fig. S1a exhibits vibrational modes at $732,810,860,900 \mathrm{~cm}^{-1}(\mathrm{~W}-\mathrm{O}-\mathrm{W}$, asymmetric vibration), $960 \mathrm{~cm}^{-1}$ (terminal W-O) and 1045 and $1086 \mathrm{~cm}^{-1}$ (P-O, asymmetric vibration). The presence of all these peaks is characteristics of the $\mathrm{PW}_{11}$ ligand [51,52], confirming its successful formation. When comparing the FTIR spectra of the $\mathrm{PW}_{11}$ potassium salt with the Eu $\left(\mathrm{PW}_{11}\right)_{2}$ tetrabutylammonium salt, we observed some minor shifts of the bands. Since the counter-ions do not affect the FTIR spectra of these polyoxometalates [51], the minor peaks dislocation was attributed to the interaction of the ligand with the $\mathrm{Eu}^{3+}$ ion. Moreover, the disappearance of a band below $750 \mathrm{~cm}^{-1}$ indicates that the interaction of the $\mathrm{PW}_{11}$ with $\mathrm{Eu}^{3+}$ ion restores the symmetry of the lacunary species to a closed structure similar to phosphotungstic acid $\left(\mathrm{H}_{3} \mathrm{PW}_{12} \mathrm{O}_{40}\right)$ [53].

Raman spectra of both $\mathrm{PW}_{11}$ and $\mathrm{Eu}\left(\mathrm{PW}_{11}\right)_{2}$ exhibit the characteristic Raman bands of Keggin-type polyoxometalates at 987, 900, 517 and $225 \mathrm{~cm}^{-1}$ [54] and the new bands above $1000 \mathrm{~cm}^{-1}$ observed only for the $\mathrm{Eu}\left(\mathrm{PW}_{11}\right)_{2}$ are related to the counterion tetrabutylammonium [55] of the europium complex (Fig. S1b). To study the Eu(PW $\left.{ }_{11}\right)$-matrix interaction, we compared the Raman spectra of pure matrix, pure Eu $\left(\mathrm{PW}_{11}\right)_{2}$ and $\mathrm{Eu}\left(\mathrm{PW}_{11}\right)_{2}$-PDMSUr hybrid membranes (Fig. S2). The peak position and relative intensity of the $\mathrm{Eu}\left(\mathrm{PW}_{11}\right)$ species remained unchanged after incorporation in the matrix, confirming its incorporation and structural integrity inside the matrix. For the same reason, we could not get any information on $\mathrm{Eu}\left(\mathrm{PW}_{11}\right)$-matrix interaction in the sample.

Thermogravimetric analysis (TGA) also confirms the formation of both materials (Figs. S3 and S4). While for $\mathrm{PW}_{11}$, a single weight loss (loss of water molecules) of $3.8 \%$ in the $100-200{ }^{\circ} \mathrm{C}$ range, a two-step weight loss was observed in case of $\mathrm{Eu}\left(\mathrm{PW}_{11}\right)_{2}$ material. The first one between $100-200{ }^{\circ} \mathrm{C}(1.1 \%)$ corresponds to the loss of water molecules and the second one between 200 and $450{ }^{\circ} \mathrm{C}$ is due to the degradation of tetrabutylammonium counterion $(24 \%)$. This weight loss is smaller than the theoretical loss expected for full substitution of $11 \mathrm{~K}^{+}$ions by tetrabutylammonium ions and thus indicates the presence of some residual $\mathrm{K}^{+}$as counterions. Nevertheless, the $\mathrm{Eu}\left(\mathrm{PW}_{11}\right)_{2}$ complex presented high solubility into organic solvents, enabling its utilization for the modification of PDMSUr matrix.

\subsection{Photoluminescent properties of the PDMSUr-Eu(PW $\left.\mathrm{W}_{11}\right)_{2}$ hybrid films}

Photoluminescent (emission and excitation) properties of $\mathrm{Eu}$ $\left(\mathrm{PW}_{11}\right)_{2}$ (powder) as well as PDMSUr-Eu( $\left(\mathrm{PW}_{11}\right)_{2}$ hybrid films were well characterized. Due to the presence of $\mathrm{Eu}\left(\mathrm{PW}_{11}\right)_{2}$ complex as 

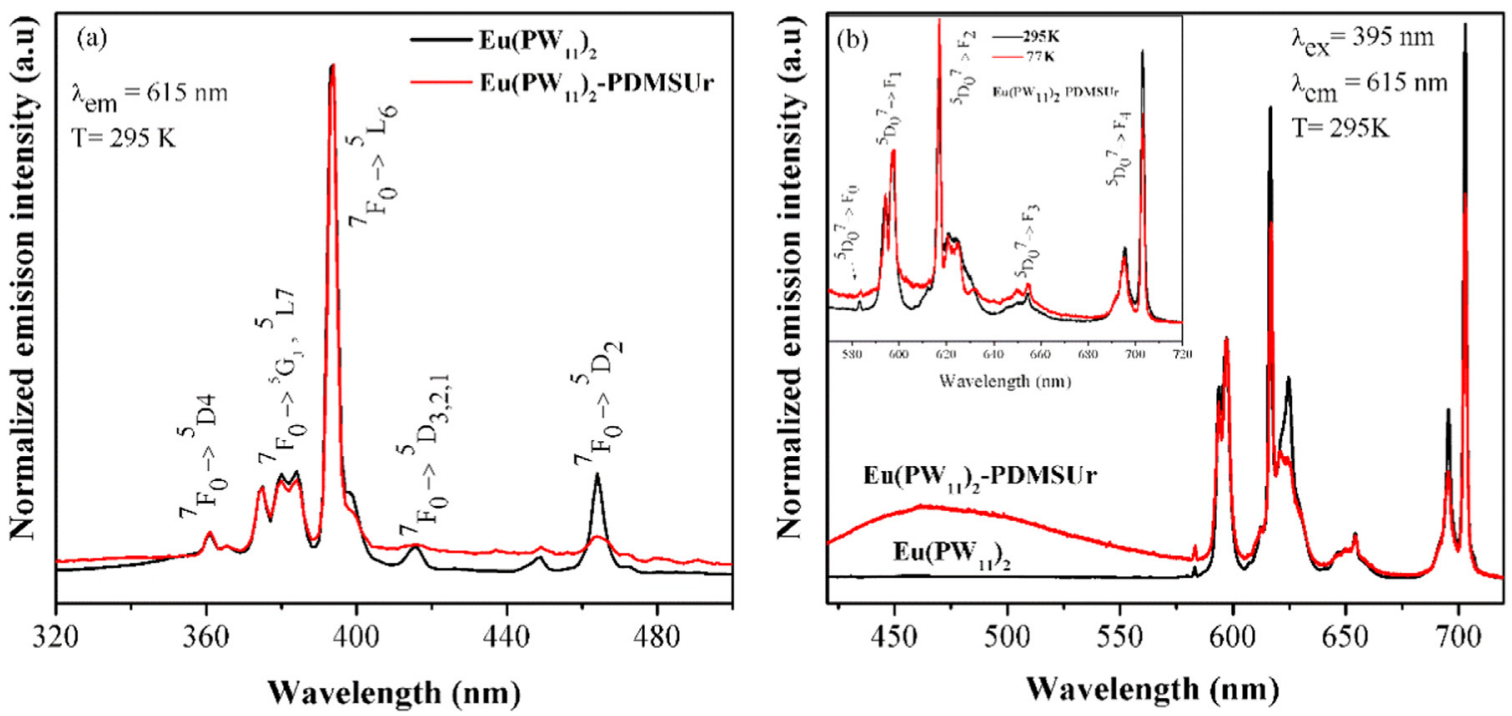

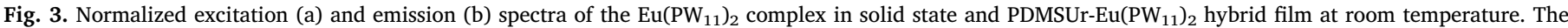

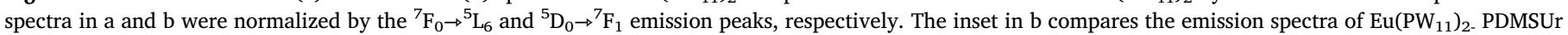
hybrid at room temperature (black line) and liquid nitrogen temperature (red line).

luminescent centers, the obtained hybrid films exhibited photoluminescent properties which are dominated by the luminescent characteristics of $\mathrm{Eu}^{3+}$ ions along with small contribution from the PDMSUr matrix. As discussed in details below, the PDMSUr matrix itself showed emission in the blue-green region which, together with the characteristic red emission of $\mathrm{Eu}\left(\mathrm{PW}_{11}\right)_{2}$ centers, led to the generation of white light. Moreover, the emission decay life time of $\mathrm{Eu}\left(\mathrm{PW}_{11}\right)_{2}$ centers also increased upon its incorporation in the matrix. These optical features of the hybrid membranes are discussed in more details below.

The room temperature excitation spectra of $\mathrm{Eu}\left(\mathrm{PW}_{11}\right)_{2}$ complex (in powder form) and $\mathrm{Eu}\left(\mathrm{PW}_{11}\right)_{2}$ complex immobilized in hybrid PDMSUr membranes are shown in Fig. 3a. Similar results were obtained when the spectra were measured at $77 \mathrm{~K}$ (Fig. S5). A prominent excitation peak at around $395 \mathrm{~nm}$, assigned to ${ }^{7} \mathrm{~F}_{0} \rightarrow{ }^{5} \mathrm{~L}_{6}$ transition of $\mathrm{Eu}^{3+}$, is observed in both samples. We could not observe the expected LMCT band in spectra of Eu( $\left(\mathrm{PW}_{11}\right)_{2}$ complex at room temperature as this band appears only at lower temperature (14 K) [48]. Upon UV (395 nm) excitation, the $\mathrm{Eu}\left(\mathrm{PW}_{11}\right)_{2}$ complex in both free and immobilized form exhibits strong luminescence emission (Fig. 3b). The emission peak at around $595 \mathrm{~nm}$ is assigned to the ${ }^{5} \mathrm{D}_{0} \rightarrow{ }^{7} \mathrm{~F}_{1}$ transition, whereas the emission at $616 \mathrm{~nm}$ is ascribed to the ${ }^{5} \mathrm{D}_{0} \rightarrow{ }^{7} \mathrm{~F}_{2}$ transition. The other three emissions appearing at 582, 652 and $695 \mathrm{~nm}$ are assigned to the ${ }^{5} \mathrm{D}_{0} \rightarrow{ }^{7} \mathrm{~F}_{0},{ }^{5} \mathrm{D}_{0} \rightarrow{ }^{7} \mathrm{~F}_{3}$ and ${ }^{5} \mathrm{D}_{0} \rightarrow{ }^{7} \mathrm{~F}_{4}$ transitions of $\mathrm{Eu}^{3+}$ ions, respectively.

Closer observation of the emission spectra of $\mathrm{Eu}\left(\mathrm{PW}_{11}\right)_{2}$ complex and $\mathrm{Eu}\left(\mathrm{PW}_{11}\right)_{2}$-PDMSUr sample shows some difference in the $610-630 \mathrm{~nm}$ region pertaining to the ${ }^{5} \mathrm{D}_{0} \rightarrow{ }^{7} \mathrm{~F}_{2}$ emission peak. This peak shows a prominent splitting and thus an additional component at around $623 \mathrm{~nm}$ in $\mathrm{Eu}\left(\mathrm{PW}_{11}\right)_{2}$ complex as compared the PDMSUr-Eu $\left(\mathrm{PW}_{11}\right)_{2}$ sample. In the later, the principle peak poorly splits and the additional component appears as shoulder on the longer wavelength side of the principle $616 \mathrm{~nm}$ peak. Since this ${ }^{5} \mathrm{D}_{0} \rightarrow{ }^{7} \mathrm{~F}_{2}$ emission is hypersensitive in nature and depends on the local environment of $\mathrm{Ln}^{3+}$ ions, we infer that $\mathrm{Eu}^{3+}$ ions are in somewhat different chemical environment in the two samples $\left(\mathrm{Eu}\left(\mathrm{PW}_{11}\right)_{2}\right.$ and $\mathrm{Eu}\left(\mathrm{PW}_{11}\right)_{2}$-PDMSur). A comparison of the normalized intensity of emission peaks of the two samples shows that the emission intensity of PDMSUr-Eu(PW $\left(\mathrm{PW}_{11}\right)_{2}$ films is lower than powder $\mathrm{Eu}\left(\mathrm{PW}_{11}\right)_{2}$. Such differences in the relative intensity of the emission peaks are clearly related to the quantity of $\mathrm{Eu}^{3+}$ centers in the two samples. Thermal deactivation may be another reason for the lower emission intensity in the $\mathrm{Eu}\left(\mathrm{PW}_{11}\right)_{2}$-PDMSUr films. However, this hypothesis is ruled out by the fact that the spectra of Eu
$\left(\mathrm{PW}_{11}\right)_{2} \mathrm{PDMSUr}$ measured at room temperature and liquid nitrogen temperature are identical (inset in Fig. 3b).

Interesting to note is the presence of an additional broad band in the blue-green region $(400-550 \mathrm{~nm})$ in the emission spectrum of the PDMSUr-Eu( $\left(\mathrm{PW}_{11}\right)_{2}$ hybrid film. To verify the origin of this emission band observed in the hybrid film, emission spectrum of pure PDMSUr matrix was collected under $395 \mathrm{~nm}$ excitation. As shown in Fig. S6, the emission spectrum of pure PDMSUr matrix also exhibits the same band in the blue-green region, thus confirming that this broad band in the spectrum of $\mathrm{Eu}\left(\mathrm{PW}_{11}\right)_{2}$.PDMSUr hybrid film arises from the matrix. This type of blue-green emission has already been observed in silica-based materials [56] and biopolymers [57] and it is related to the electronhole recombination in such hybrid matrices. As shown in Fig. 4, this blue-green emission plays an important role in the generation of white light. Considering the emission from both PDMSUr matrix and $\mathrm{Eu}^{3+}$

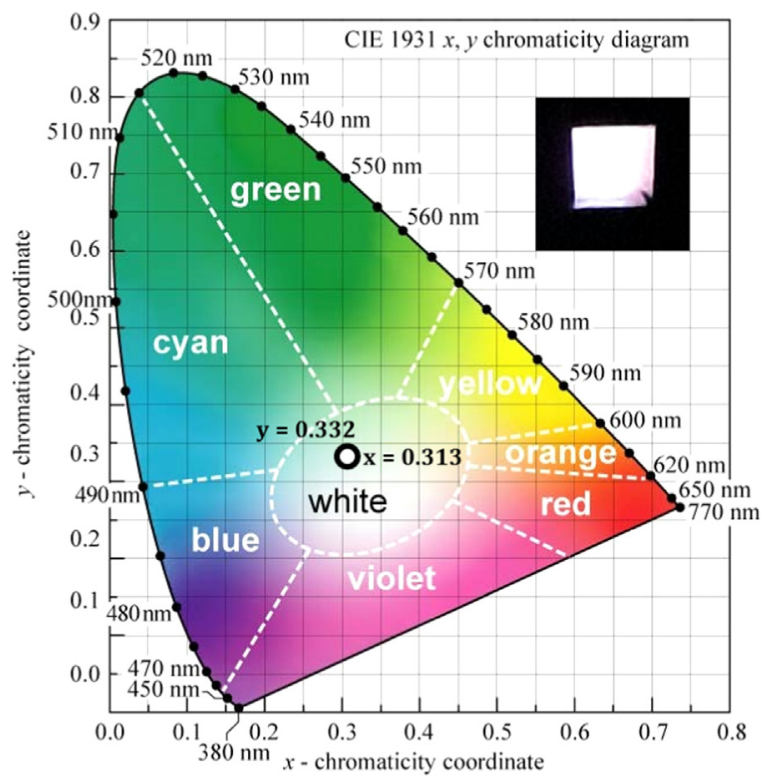

Fig. 4. The CIE 1931 color coordinate diagram demonstrating that the calculated color coordinate $(\mathrm{x}, \mathrm{y})$ values for the PDMSUr modified with $\mathrm{Eu}\left(\mathrm{PW}_{11}\right)_{2}$ films lie in the white region (marked circle). Inset: digital photograph of the material irradiated under $395 \mathrm{~nm}$ showing its white emission. 
ions, upon $395 \mathrm{~nm}$ excitation, the PDMSUr-Eu(PW $\left(\mathrm{PW}_{11}\right)_{2}$ hybrid film is able to generate white light (see digital photo in inset of Fig. 4). Analysis of color coordinates presents an intersection at $\mathrm{x}=0.313$ and $y=0.332$ that falls within the white light region of the chromaticity diagram. Moreover, the calculated color correlated temperature (CCT) of the sample is $4888 \mathrm{~K}$ which may be considered as neutral white light. The color rendering index (CRI) was found to be 61. Although this CRI value is considered low, it is important to mention that the CRI calculations underestimate this value for emitters with sharp emission band [58], such as the $\mathrm{Eu}^{3+}$ ion in our case. Moreover, an increase in emission decay lifetime of $\mathrm{Eu}^{3+}$ from $1.49 \pm 0.01 \mathrm{~ms}$ to $3.04 \pm 0.1 \mathrm{~ms}$ (Figs. S7 and S8) is observed once $\mathrm{Eu}\left(\mathrm{PW}_{11}\right)_{2}$ is incorporated in the PDMSUr matrix. We assume that the difference in lifetime of the excited state ${ }^{5} \mathrm{D}_{0}$ may be related to the difference in concentration of $\mathrm{Eu}^{3+}$ ion in the two samples. A higher concentration of $\mathrm{Eu}^{3+}$ ions (decreased distance between $\mathrm{Eu}^{3+}$ ions) in $\mathrm{Eu}\left(\mathrm{PW}_{11}\right)_{2}$ powder sample possibly leads to an increase in nonradiative decay rate of $\mathrm{Eu}^{3+}$ ions, thus decreasing their average lifetime. The photostability of the $\mathrm{Eu}\left(\mathrm{PW}_{11}\right)_{2}$-PDMSUr hybrid films was studied under continuation UV irradiation at $395 \mathrm{~nm}$. No significant changes in the emission characteristic were observed after continuous UV irradiation for two hours (Fig. S9), confirming the photostable nature of the hybrid films. The combination of PDMSUr matrix and $\mathrm{Eu}\left(\mathrm{PW}_{11}\right)_{2}$ emission centers in the form of luminescent, flexible and self-supporting films not only provides white light upon UV excitation but can also offer other relevant advantages such as high flexibility and processability, emphasizing the potential of this material for potential application as a white emitters [57].

\section{Conclusions}

We have successfully prepared luminescent and highly transparent self-supporting hybrid films capable of generating white light upon UV excitation. These hybrid films are based on PDMSUr as polymeric matrix and $\mathrm{Eu}\left(\mathrm{PW}_{11}\right)_{2}$ as the luminescent component. The greener PDMSUr matrix, which is obtained from $\mathrm{CO}_{2}$ fixation in the polymer backbone, plays important role in obtaining materials with desired mechanical and optical properties. Together with the characteristic red emission of $\mathrm{Eu}^{3+}$, the blue-green emission from the PDMSUr matrix itself allows to generate white light upon UV excitation. Moreover, an increase in emission decay lifetime (from around $1.5 \mathrm{~ms}$ to $3 \mathrm{~ms}$ ) is observed when $\mathrm{Eu}\left(\mathrm{PW}_{11}\right)_{2}$ is incorporated in the hybrid matrix. Finally, the hybrid films obtained are flexible and self-supporting in nature and can be considered as suitable candidates for potential applications based on white light generation, opening a new field of the $\mathrm{CO}_{2}$ derived PHUs into the optoelectronic materials.

\section{Conflicts of interest}

The authors have no competing and/or relevant financial interest(s) to disclose.

\section{Acknowledgment}

M.B. Simões acknowledges financial support from Coordination of Superior Level Staff Improvement (CAPES, Brazil) under grant number PROEX 1480648. S. Ullah and C. Hazra acknowledge financial support from the São Paulo Research Foundation (FAPESP, Brazil) under fellowship grant number 2015/18733-0 and 2015/22875-4, respectively. M. Wong Chi Man is grateful to the French Consulate of São Paulo and to Universidade Estadual Paulista "Júlio de Mesquita Filho" (UNESP) for an academic chair appointment in São Paulo state.

\section{Appendix A. Supplementary material}

Supplementary data associated with this article can be found in the online version at http://dx.doi.org/10.1016/j.jlumin.2018.04.041.

\section{References}

[1] S.D. Cotton, Lanthanide and Actinide Chemistry, John Wiley, 2006.

[2] A. Kitai, Luminescent Materials and Applications, John Wiley [distributor], Chichester, 2008.

[3] V.V. Utochnikova, N.N. Solodukhin, A.N. Aslandukov, L. Marciniak, I.S. Bushmarinov, A.A. Vashchenko, N.P. Kuzmina, Lanthanide tetrafluorobenzoates as emitters for OLEDs: new approach for host selection, Org. Electron. 44 (2017) 85-93, http://dx.doi.org/10.1016/j.orgel.2017.01.026.

[4] P. Yasaka, J. Kaewkhao, Luminescence from Lanthanides-doped Glasses and Applications: A Review, 2015, pp. 4-15, 〈http://dx.doi.org/10.1109/icici-bme. 2015.7401304>.

[5] L.D. Carlos, R.A.S. Ferreira, V. de Zea Bermudez, B. Julián-López, P. Escribano, Progress on lanthanide-based organic-inorganic hybrid phosphors, Chem. Soc. Rev. 40 (2011) 536-549, http://dx.doi.org/10.1039/c0cs00069h.

[6] J.H. Kim, P.H. Holloway, Near-infrared-electroluminescent light-emitting planar optical sources based on gallium nitride doped with rare earths, Adv. Mater. 17 (2005) 91-96, http://dx.doi.org/10.1002/adma.200306402.

[7] A. de Bettencourt-Dias, Lanthanide-based emitting materials in light-emitting diodes, Dalton T (2007) 2229, http://dx.doi.org/10.1039/b702341c.

[8] A.J. Steckl, M. Garter, D.S. Lee, J. Heikenfeld, R. Birkhahn, Blue emission from Tmdoped GaN electroluminescent devices, Appl. Phys. Lett. 75 (1999) 2184-2186, http://dx.doi.org/10.1063/1.124958.

[9] F. Auzel, Upconversion and anti-stokes processes with $\mathrm{f}$ and $\mathrm{d}$ ions in solids, Chem. Rev. 104 (2004) 139-174, http://dx.doi.org/10.1021/cr020357g.

[10] C. Li, J. Lin, Rare earth fluoride nano-/microcrystals: synthesis, surface modification and application, J. Mater. Chem. 20 (2010) 6831, http://dx.doi.org/10.1039/ c0jm00031k.

[11] S. Heer, O. Lehmann, M. Haase, H.-U. Güdel, Blue, green, and red upconversion emission from lanthanide-doped $\mathrm{LuPO}_{4}$ and $\mathrm{YbPO}_{4}$ nanocrystals in a transparent colloidal solution, Angew. Chem. Int. Ed. 42 (2003) 3179-3182, http://dx.doi.org/ 10.1002/anie.200351091.

[12] F. Wang, X. Liu, Upconversion multicolor fine-tuning: visible to near-infrared emission from lanthanide-doped $\mathrm{NaYF}_{4}$ nanoparticles, J. Am. Chem. Soc. 130 (2008) 5642-5643, http://dx.doi.org/10.1021/ja800868a.

[13] H. Schäfer, P. Ptacek, K. Kömpe, M. Haase, Lanthanide-doped $\mathrm{NaYF}_{4}$ nanocrystals in aqueous solution displaying strong up-conversion emission, Chem. Mater. 19 (2007) 1396-1400, http://dx.doi.org/10.1021/cm062385b.

[14] V. Mahalingam, F. Mangiarini, F. Vetrone, V. Venkatramu, M. Bettinelli, A. Speghini, J.A. Capobianco, Bright white upconversion emission from $\mathrm{Tm}^{3+}$, $\mathrm{Yb}^{3+} / \mathrm{Er}^{3+}$-doped $\mathrm{Lu}_{3} \mathrm{Ga}_{5} \mathrm{O}_{12}$ nanocrystals, J. Phys. Chem. C 112 (2008) 17745-17749, http://dx.doi.org/10.1021/jp8076479.

[15] J. Silver, M.I. Martinez-Rubio, T.G. Ireland, G.R. Fern, R. Withnall, The effect of particle morphology and crystallite size on the upconversion luminescence properties of erbium and ytterbium co-doped yttrium oxide phosphors, J. Phys. Chem. B 105 (2001) 948-953, http://dx.doi.org/10.1021/jp002778c.

[16] M.B.S. Botelho, T.B. de Queiroz, H. Eckert, A.S.S. de Camargo, Efficient luminescent materials based on the incorporation of a Eu(III)tris-(bipyridine-carboxylate) complex in mesoporous hybrid silicate hosts, J. Lumin. 170 (2016) 619-626, http://dx.doi.org/10.1016/j.jlumin.2015.08.072.

[17] J. Graffion, X. Cattoën, M. Wong Chi Man, V.R. Fernandes, P.S. André, R.A.S. Ferreira, L.D. Carlos, Modulating the photoluminescence of bridged silsesquioxanes incorporating $\mathrm{Eu}^{3+}$-complexedn, $\mathrm{n}^{\prime}$-diureido-2,2'-bipyridine isomers: application for luminescent solar concentrators, Chem. Mater. 23 (2011) 4773-4782, http://dx.doi.org/10.1021/cm2019026.

[18] V.T. Freitas, L. Fu, A.M. Cojocariu, X. Cattoën, J.R. Bartlett, R. Le Parc, J.L. Bantignies, M. Wong Chi Man, P.S. André, R.A.S. Ferreira, L.D. Carlos, $\mathrm{Eu}^{3+}$ based bridged silsesquioxanes for transparent luminescent solar concentrators, ACS Appl. Mater. Interfaces 7 (2015), pp. 8770-8778, http://dx.doi.org/10.1021/ acsami.5b01281.

[19] Z. Cheng, P. Ma, Z. Hou, W. Wang, Y. Dai, X. Zhai, J. Lin, $\mathrm{YVO}_{4}: \mathrm{Eu}^{3+}$ functionalized porous silica submicrospheres as delivery carriers of doxorubicin, Dalton Trans. 41 (2012) 1481-1489, http://dx.doi.org/10.1039/c1dt11399b.

[20] G. Chen, H. Liu, H. Liang, G. Somesfalean, Z. Zhang, Upconversion emission enhancement in $\mathrm{Yb}^{3+} / \mathrm{Er}^{3+}$-Codoped $\mathrm{Y}_{2} \mathrm{O}_{3}$ nanocrystals by tridoping with $\mathrm{Li}^{+}$Ions, $\mathrm{J}$. Phys. Chem. C 112 (2008) 12030-12036, http://dx.doi.org/10.1021/jp804064g.

[21] H. Guo, N. Dong, M. Yin, W. Zhang, L. Lou, S. Xia, Visible upconversion in rare earth ion-doped $\mathrm{Gd}_{2} \mathrm{O}_{3}$ nanocrystals, J. Phys. Chem. B 108 (2004) 19205-19209, http://dx.doi.org/10.1021/jp048072q.

[22] S. Tabanli, G. Bilir, G. Eryurek, Color tunable up-conversion emission from $\mathrm{Er}^{3+}: \mathrm{Y}_{2} \mathrm{O}_{3}$ nanoparticles embedded in PMMA matrix, J. Lumin. 182 (2017) 146-153, http://dx.doi.org/10.1016/j.jlumin.2016.10.009.

[23] L.R. Lima, M.L. Moraes, K. Nigoghossian, M.F.S. Peres, S.J.L. Ribeiro, Silk fibroinantigenic peptides- $\mathrm{YVO}_{4}: \mathrm{Eu}^{3+}$ nanostructured thin films as sensors for hepatitis C, J. Lumin. 170 (2016) 375-379, http://dx.doi.org/10.1016/j.jlumin.2015.08.039.

[24] V. Mahalingam, C. Hazra, R. Naccache, F. Vetrone, J.A. Capobianco, Enhancing the color purity of the green upconversion emission from $\mathrm{Er}^{3+} / \mathrm{Yb}^{3+}$-doped $\mathrm{GdVO}_{4}$ nanocrystals via tuning of the sensitizer concentration, J. Mater. Chem. C 1 (2013) 6536, http://dx.doi.org/10.1039/c3tc31328j.

[25] C. Hazra, S. Sarkar, V. Mahalingam, Selective reduction of visible upconversion emissions induced by $\mathrm{Bi}^{3+}$ in $\mathrm{Tm}^{3+} / \mathrm{Yb}^{3+}$-doped $\mathrm{Y}_{0.89-\mathrm{x}} \mathrm{Bi}_{\mathrm{x}} \mathrm{VO}_{4}$ microcrystals, RSC Adv. 2 (2012) 6926, http://dx.doi.org/10.1039/c2ra20239e.

[26] C. Hazra, V. Mahalingam, Water dispersible $\mathrm{Eu}^{3+}$-doped $\mathrm{NaGd}\left(\mathrm{SO}_{4}\right)_{2} \cdot \mathrm{H}_{2} \mathrm{O}$ nanorods 
for selective $\mathrm{Fe}^{3+}$ sensing applications, RSC Adv. 3 (2013) 9197, http://dx.doi.org/ 10.1039/c3ra41343h.

[27] B.S. Bassil, U. Kortz, Recent advances in lanthanide-containing polyoxotungstates, J. Inorg. Gen. Chem. 636 (2010) 9, http://dx.doi.org/10.1002/zaac.201000201/ full.

[28] H.Z.S. Wang, Foundation of up-conversion nanoparticles, in: R.-S. Liu (Ed.), Phosphors, Up Conversion Nano Particles, Quantum Dots and Their Applications, Springer, Singapore, 2016, pp. 437-471.

[29] F. Wang, X. Liu, Recent advances in the chemistry of lanthanide-doped upconversion nanocrystals, Chem. Soc. Rev. 38 (2009) 976, http://dx.doi.org/10.1039/ b809132n.

[30] L.D. Carlos, R.A.S. Ferreira, Vd.Z. Bermudez, S.J.L. Ribeiro, Lanthanide-containing light-emitting organic-inorganic hybrids: a bet on the future, Adv. Mater. 21 (2009) 509-534, http://dx.doi.org/10.1002/adma.200801635.

[31] R.A.S. Ferreira, P.S. André, L.D. Carlos, Organic-inorganic hybrid materials towards passive and active architectures for the next generation of optical networks, Opt. Mater. 32 (2010) 1397-1409, http://dx.doi.org/10.1016/j.optmat.2010.06.019.

[32] IPCC, Climate Change 2007: The Physical Science Basis. Contribution of Working Group I to the Fourth Assessment Report of the Intergovernmental Panel on Climate Change, Cambridge University Press, 2007, p. 2007.

[33] B. Metz, IPCC Special Report on Carbon Dioxide Capture and Storage, Cambridge University Press for the Intergovernmental Panel on Climate Change, 2005.

[34] S.A. Didas, S. Choi, W. Chaikittisilp, C.W. Jones, Amine-oxide hybrid materials for $\mathrm{CO}_{2}$ capture from ambient air, Acc. Chem. Res. 48 (2015) 2680-2687, http://dx. doi.org/10.1021/acs.accounts.5b00284.

[35] A. Samanta, A. Zhao, G.K.H. Shimizu, P. Sarkar, R. Gupta, Post-combustion $\mathrm{CO}_{2}$ capture using solid sorbents: a review, Ind. Eng. Chem. Res. 51 (2012) 1438-1463, http://dx.doi.org/10.1021/ie200686q.

[36] M. Aresta, Carbon dioxide: utilization options to reduce its accumulation in the atmosphere, in: M. Aresta (Ed.), Carbon Dioxide as Chemical Feedstock, John Wiley, 2010, pp. 1-13.

[37] A.J. Hunt, E.H.K. Sin, R. Marriott, J.H. Clark, Generation, capture, and utilization of industrial carbon dioxide, Chemsuschem 3 (2010) 306-322, http://dx.doi.org/10. 1002/cssc.200900169.

[38] O.L. Figovsky, L. Shapovalov, O. Axenov, Advanced coatings based upon non-isocyanate polyurethanes for industrial applications, Surf. Coat. Int. Part B: Coat. Trans. 87 (2004) 83-90, http://dx.doi.org/10.1007/Bf02699601.

[39] H. Blattmann, M. Fleischer, M. Bähr, R. Mülhaupt, Isocyanate- and phosgene-free routes to polyfunctional cyclic carbonates and green polyurethanes by fixation of carbon dioxide, Macromol. Rapid Commun. 35 (2014) 1238-1254, http://dx.doi. org/10.1002/marc.201400209.

[40] B. Nohra, L. Candy, J.-F. Blanco, C. Guerin, Y. Raoul, Z. Mouloungui, From petrochemical polyurethanes to biobased polyhydroxyurethanes, Macromolecules 46 (2013) 3771-3792, http://dx.doi.org/10.1021/ma400197c.

[41] M.S. Kathalewar, P.B. Joshi, A.S. Sabnis, V.C. Malshe, Non-isocyanate polyurethanes: from chemistry to applications, RSC Adv. 3 (2013) 4110, http://dx.doi. org/10.1039/c2ra21938g.

[42] H. Blattmann, M. Lauth, R. Mülhaupt, Flexible and bio-based nonisocyanate polyurethane (NIPU) foams, Macromol. Mater. Eng. 301 (2016) 944-952, http://dx.doi. org/10.1002/mame.201600141.

[43] A. Cornille, C. Guillet, S. Benyahya, C. Negrell, B. Boutevin, S. Caillol, Room temperature flexible isocyanate-free polyurethane foams, Eur. Polym. J. 84 (2016) 873-888, http://dx.doi.org/10.1016/j.eurpolymj.2016.05.032.

[44] A. Bossion, G.O. Jones, D. Taton, D. Mecerreyes, J.L. Hedrick, Z.Y. Ong, Y.Y. Yang, H. Sardon, Non-isocyanate polyurethane soft nanoparticles obtained by surfactant- assisted interfacial polymerization, Langmuir 33 (2017) 1959-1968, http://dx.doi. org/10.1021/acs.langmuir.6b04242.

[45] K.M.F. Rossi de Aguiar, E.P. Ferreira-Neto, S. Blunk, J.F. Schneider, C.A. Picon, C.M. Lepienski, K. Rischka, U.P. Rodrigues-Filho, Hybrid urethanesil coatings for inorganic surfaces produced by isocyanate-free and sol-gel routes: synthesis and characterization, RSC Adv. 6 (2016) 19160-19172, http://dx.doi.org/10.1039/ c5ra24331a.

[46] K.M.F. Rossi de Aguiar, U. Specht, J.F. Maass, D. Salz, C.A. Picon, P.L.M. Noeske, K. Rischka, U.P. Rodrigues-Filho, Surface modification by physical treatments on biomedical grade metals to improve adhesion for bonding hybrid non-isocyanate urethanes, RSC Adv. 6 (2016) 47203-47211, http://dx.doi.org/10.1039/ c6ra05397a.

[47] K.M.F. Rossi de Aguiar, V.G. Santos, M.N. Eberlin, K. Rischka, M. Noeske, G. Tremiliosi-Filho, U.P. Rodrigues-Filho, Efficient green synthesis of bis(cyclic carbonate)poly(dimethylsiloxane) derivative using $\mathrm{CO}_{2}$ addition: a novel precursor for synthesis of urethanes, RSC Adv. 4 (2014) 24334, http://dx.doi.org/10.1039/ c4ra03846k.

[48] C.S. Neves, C.M. Granadeiro, L. Cunha-Silva, D. Ananias, S. Gago, G. Feio, P.A. Carvalho, P. Eaton, S.S. Balula, E. Pereira, Europium polyoxometalates encapsulated in silica nanoparticles - characterization and photoluminescence studies, Eur. J. Inorg. Chem. (2013) 2877-2886, http://dx.doi.org/10.1002/ejic. 201201482.

[49] N. Karak, Biobased hyperbranched polyurethane, in: N. Karak (Ed.), Biobased Smart Polyurethane Nanocomposites: from Synthesis to Applications, RSC, 2017, pp. $1-40$.

[50] M.B. Anderson, Tetrabutylammonium dodecatungstophosphate, e-EROS Encycl. Reag. Org. Synth. (2013), http://dx.doi.org/10.1002/047084289X.rn01585.

[51] S. Lis, S. But, G. Meinrath, Synthesis and spectroscopic characterisation of chosen heteropolyanions and their Ln(III) complexes containing tetrabutylammonium counter ion, J. Alloy. Compd. 374 (2004) 366-370, http://dx.doi.org/10.1016/j. jallcom.2003.11.126.

[52] R. Contant, Relations entre les tungstophosphates apparentés à l'anion $\mathrm{PW}_{12} \mathrm{O}_{40}{ }^{3-}$. Synthèse et propriétés d'un nouveau polyoxotungstophosphate lacunaire $\mathrm{K}_{10} \mathrm{P}_{2} \mathrm{~W}_{20} \mathrm{O}_{70} \cdot 24 \mathrm{H}_{2} \mathrm{O}$, Can. J. Chem. 65 (1987) 568-573, http://dx.doi.org/10. $1139 / \mathrm{v} 87-100$.

[53] Y. Zhang, H. Lü, L. Wang, Y. Zhang, P. Liu, H. Han, Z. Jiang, C. Li, The oxidation of benzothiophene using the Keggin-type lacunary polytungstophosphate as catalysts in emulsion, J. Mol. Catal. A-Chem. 332 (2010) 59-64, http://dx.doi.org/10.1016/ j.molcata.2010.08.021.

[54] A.J. Bridgeman, Density functional study of the vibrational frequencies of $\alpha$-Keggin heteropolyanions, Chem. Phys. 287 (2003) 55-69, http://dx.doi.org/10.1016/ s0301-0104(02)00978-3.

[55] B. Alcaide, P. Almendros, A.M. González, A. Luna, S. Martínez-Ramírez, Palladium nanoparticles in water: a reusable catalytic system for the cycloetherification or benzannulation of $\alpha$-allenols, Adv. Synth. Catal. 358 (2016) 2000-2006, http://dx. doi.org/10.1002/adsc.201501132.

[56] M. Fernandes, M.C. Gonçalves, V. de Zea Bermudez, R.A. Sá Ferreira, L.D. Carlos, A. Charas, J. Morgado, Optical material composed of a di-urethanesil host hybrid and a europium complex, J. Alloy. Compd. 451 (2008) 201-205, http://dx.doi.org/ 10.1016/j.jallcom.2007.04.237.

[57] R. Alves, L.P. Ravaro, A. Pawlicka, M.M. Silva, A.S.Sd Camargo, Eco-friendly luminescent hybrid materials based on $\mathrm{Eu}(\mathrm{III})$ and $\mathrm{Li}(\mathrm{I})$ co-doped chitosan, J. Braz Chem. Soc. (2015), http://dx.doi.org/10.5935/0103-5053.20150267.

[58] D. Malacara, Color Vision and Colorimetry: Theory and Applications, 2nd ed., SPIE (Society of Photo-optical Instrumentation Engineers), 2011. 